\title{
FIXED POINT THEOREMS FOR GENERALIZED F-CONTRACTIONS AND GENERALIZED F-SUZUKI-CONTRACTIONS IN COMPLETE DISLOCATED $S_{b}$-METRIC SPACES
}

\section{HAMID MEHRAVARAN, MAHNAZ KHANEHGIR* AND REZA ALLAHYARI}

Department of Mathematics, Mashhad Branch, Islamic Azad University, Mashhad, Iran

${ }^{*}$ Corresponding author: khanehgir@mshdiau.ac.ir

\begin{abstract}
In this paper, first we describe the notion of dislocated $S_{b}$-metric space and then we introduce the new notions of generalized $F$-contraction and generalized $F$-Suzuki-contraction in the setup of dislocated $S_{b}$-metric spaces. We establish some fixed point theorems involving these contractions in complete dislocated $S_{b}$-metric spaces. We also furnish some examples to verify the effectiveness and applicability of our results.
\end{abstract}

\section{Introduction AND Preliminaries}

Bakhtin [1] and Czerwik [2] introduced $b$-metric spaces and proved the contraction principle in this framework. In recent times, many authors obtained fixed point results for single-valued or set-valued functions, in the setting of $b$-metric spaces.

In 2012, Sedghi et al. [11] introduced the concept of $S$-metric space by modifying $D$-metric and $G$-metric spaces and proved some fixed point theorems for a self-mapping on a complete $S$-metric space. After that

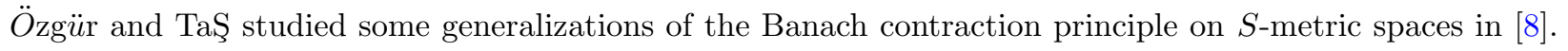
They also obtained some fixed point theorems for the Rhoades' contractive condition on $S$-metric spaces [7]. Sedghi et al. [10] introduced the concept of $S_{b}$-metric space as a generalization of $S$-metric space and proved some coupled common fixed point theorems in $S_{b}$-metric space. Kishore et al. [4] proved some fixed point

Received 2019-03-11; accepted 2019-07-24; published 2019-09-02.

2010 Mathematics Subject Classification. 47H09, 47H10.

Key words and phrases. Dislocated metric space; Fixed point; Generalized $F$-contraction; Generalized $F$-Suzuki-contraction; $S_{b}$-Metric space.

(C) 2019 Authors retain the copyrights of their papers, and all open access articles are distributed under the terms of the Creative Commons Attribution License. 
theorems for generalized contractive conditions in partially ordered complete $S_{b}$-metric spaces and gave some applications to integral equations and homotopy theory.

On the other hand, Wardowski [12] introduced a new contraction, the so-called $F$-contraction, and obtained a fixed point result as a generalization of the Banach contraction principle. Thereafter, Dung and Hang [3] studied the notion of a generalized $F$-contraction and established certain fixed point theorems for such mappings. Recently, Piri and Kumam [6] extended the fixed point results of [12] by introducing a generalized $F$-Suzuki-contraction in $b$-metric spaces.

Motivated by the aforementioned works, in this paper, we first introduce the notion of dislocated $S_{b^{-}}$metric space and then we describe some fixed point results of [3], [6] by introducing generalized $F$-contractions and generalized $F$-Suzuki-contractions in dislocated $S_{b}$-metric spaces. We begin with some basic well-known definitions and results which will be used further on.

Throughout this paper $\mathbb{R}, \mathbb{R}_{+}, \mathbb{N}$ denote the set of all real numbers, the set of all nonnegative real numbers and the set of all positive integers, respectively.

Definition 1.1. [11] Let $X$ be a nonempty set. An $S$-metric on $X$ is a function $S: X^{3} \rightarrow \mathbb{R}_{+}$that satisfies the following conditions:

(S1) $0<S(x, y, z)$ for each $x, y, z \in X$ with $x \neq y \neq z \neq x$,

(S2) $S(x, y, z)=0$ if and only if $x=y=z$,

(S3) $S(x, y, z) \leq S(x, x, a)+S(y, y, a)+S(z, z, a)$ for each $x, y, z, a \in X$.

Then the pair $(X, S)$ is called an $S$-metric space.

Definition 1.2. [10] Let $X$ be a nonempty set and $b \geq 1$ be a given real number. Suppose that a mapping $S_{b}: X^{3} \rightarrow \mathbb{R}_{+}$satisfies:

$\left(S_{b} 1\right) 0<S_{b}(x, y, z)$ for all $x, y, z \in X$ with $x \neq y \neq z \neq x$,

$\left(S_{b} 2\right) S_{b}(x, y, z)=0$ if and only if $x=y=z$,

$\left(S_{b} 3\right) S_{b}(x, y, z) \leq b\left(S_{b}(x, x, a)+S_{b}(y, y, a)+S_{b}(z, z, a)\right)$ for all $x, y, z, a \in X$.

Then $S_{b}$ is called an $S_{b}$-metric on $X$ and the pair $\left(X, S_{b}\right)$ is called an $S_{b}$-metric space.

Definition 1.3. [10] If $\left(X, S_{b}\right)$ is an $S_{b}$-metric space, a sequence $\left\{x_{n}\right\}$ in $X$ is said to be:

(1) Cauchy sequence if, for each $\varepsilon>0$, there exists $n_{0} \in \mathbb{N}$ such that $S_{b}\left(x_{n}, x_{n}, x_{m}\right)$ $<\varepsilon$ for all $m, n \geq n_{0}$.

(2) convergent to a point $x \in X$ if, for each $\varepsilon>0$, there exists a positive integer $n_{0}$ such that $S_{b}\left(x_{n}, x_{n}, x\right)<\varepsilon$ or $S_{b}\left(x, x, x_{n}\right)<\varepsilon$ for all $n \geq n_{0}$, and we denote by $\lim _{n \rightarrow \infty} x_{n}=x$.

Definition 1.4. [10] An $S_{b}$-metric space $\left(X, S_{b}\right)$ is called complete if every Cauchy sequence is convergent in $X$. 
Example 1.1. [9] Let $X=\mathbb{R}$. Define $S_{b}: X^{3} \rightarrow \mathbb{R}_{+}$by $S_{b}(x, y, z)=|x-z|+|y-z|$ for all $x, y, z \in X$. Then $\left(X, S_{b}\right)$ is a complete $S_{b}$-metric space with $b=2$.

Definition 1.5. Let $\left(X, S_{b}\right)$ be an $S_{b}$-metric space. Then $S_{b}$ is called symmetric if

$$
S_{b}(x, x, y)=S_{b}(y, y, x)
$$

for all $x, y \in X$.

It is easy to see that the symmetry condition (1.1) is automatically satisfied by an $S$-metric [11].

We conclude this section recalling the following fixed point theorems of Dung and Hang [3] and Piri and Kumam [6]. For this, we need some preliminaries.

Definition 1.6. [12] Let $\mathcal{F}$ be the family of all functions $F:(0,+\infty) \rightarrow \mathbb{R}$ such that:

(F1) $F$ is strictly increasing, that is for all $\alpha, \beta \in(0,+\infty)$ such that $\alpha<\beta, F(\alpha)<F(\beta)$,

(F2) for each sequence $\left\{\alpha_{n}\right\}$ of positive numbers, $\lim _{n \rightarrow+\infty} \alpha_{n}=0$ if and only if $\lim _{n \rightarrow+\infty} F\left(\alpha_{n}\right)=-\infty$,

(F3) there exists $k \in(0,1)$ such that $\lim _{\alpha \rightarrow 0^{+}} \alpha^{k} F(\alpha)=0$.

In 2014, Piri and Kumam [5] described a large class of functions by replacing the condition (F3) in the above definition with the following one:

$\left(F 3^{\prime}\right) \quad F$ is continuous on $(0,+\infty)$.

They denote by $\mathfrak{F}$ the family of all functions $F:(0,+\infty) \rightarrow \mathbb{R}$ which satisfy conditions $(F 1),(F 2)$, and $\left(F 3^{\prime}\right)$.

Example 1.2. (see [5], [13]) The following functions $F:(0,+\infty) \rightarrow \mathbb{R}$ are the elements of $\mathfrak{F}$.

(1) $F(\alpha)=-\frac{1}{\sqrt{\alpha}}$

(2) $F(\alpha)=-\frac{1}{\alpha}+\alpha$,

(3) $F(\alpha)=\frac{1}{1-e^{\alpha}}$,

(4) $F(\alpha)=\ln \alpha$,

(5) $F(\alpha)=\ln \alpha+\alpha$.

Definition 1.7. [3] Let $(X, d)$ be a metric space. A mapping $T: X \rightarrow X$ is said to be a generalized $F$-contraction on $(X, d)$ if there exist $F \in \mathcal{F}$ and $\tau>0$ such that, for all $x, y \in X$,

$$
d(T x, T y)>0 \Rightarrow \tau+F(d(T x, T y)) \leq F(N(x, y)),
$$

in which

$$
N(x, y)=\max \left\{d(x, y), d(x, T x), d(y, T y), \frac{d(x, T y)+d(y, T x)}{2}, \frac{d\left(T^{2} x, x\right)+d\left(T^{2} x, T y\right)}{2}, d\left(T^{2} x, T x\right), d\left(T^{2} x, y\right), d\left(T^{2} x, T y\right)\right\} .
$$


Theorem 1.1. [3] Let $(X, d)$ be a complete metric space and let $T: X \rightarrow X$ be a generalized $F$-contraction mapping. If $T$ or $F$ is continuous, then $T$ has a unique fixed point $x^{*} \in X$ and for every $x \in X$ the sequence $\left\{T^{n} x\right\}$ converges to $x^{*}$.

We use $\mathfrak{F}_{G}$ to denote the set of all functions $F:(0,+\infty) \rightarrow \mathbb{R}$ which satisfy conditions $(F 1)$ and $\left(F 3^{\prime}\right)$ and $\Psi$ to denote the set of all functions $\psi: \mathbb{R}_{+} \rightarrow \mathbb{R}_{+}$such that $\psi$ is continuous and $\psi(t)=0$ if and only if $t=0($ see $[6])$.

Definition 1.8. [6] Let $(X, d)$ be a b-metric space. A self-mapping $T: X \rightarrow X$ is said to be a generalized $F$-Suzuki-contraction if there exists $F \in \mathfrak{F}_{G}$ such that, for all $x, y \in X$ with $x \neq y$,

$$
\frac{1}{2 s} d(x, T x)<d(x, y) \Rightarrow F\left(s^{5} d(T x, T y)\right) \leq F\left(M_{T}(x, y)\right)-\psi\left(M_{T}(x, y)\right),
$$

in which $\psi \in \Psi$ and

$$
\begin{array}{r}
M_{T}(x, y)=\max \left\{d(x, y), d\left(T^{2} x, y\right), \frac{d(T x, y)+d(x, T y)}{2 s}, \frac{d\left(T^{2} x, x\right)+d\left(T^{2} x, T y\right)}{2 s},\right. \\
\left.d\left(T^{2} x, T y\right)+d\left(T^{2} x, T x\right), d\left(T^{2} x, T y\right)+d(T x, x), d(T x, y)+d(y, T y)\right\} .
\end{array}
$$

Theorem 1.2. [6] Let $(X, d)$ be a complete b-metric space and $T: X \rightarrow X$ be a generalized $F$-Suzukicontraction. Then $T$ has a unique fixed point $x^{*} \in X$ and for every $x \in X$ the sequence $\left\{T^{n} x\right\}$ converges to $x^{*}$.

\section{Main results}

In this section, we first introduce the concept of dislocated $S_{b}$-metric space and then we demonstrate some fixed point results for generalized $F$-contractions and generalized $F$-Suzuki-contractions in such spaces. Our results are remarkable for two reasons: first dislocated $S_{b^{-}}$metric is more general, second the contractivity condition involves auxiliary functions form a wider class.

Definition 2.1. Let $X$ be a nonempty set and $b \geq 1$ be a given real number. A mapping $S_{b}: X^{3} \rightarrow \mathbb{R}_{+}$is a dislocated $S_{b}$-metric if, for all $x, y, z, a \in X$, the following conditions are satisfied:

$\left(d S_{b} 1\right) S_{b}(x, y, z)=0$ implies $x=y=z$,

$\left(d S_{b} 2\right) S_{b}(x, y, z) \leq b\left(S_{b}(x, x, a)+S_{b}(y, y, a)+S_{b}(z, z, a)\right)$.

$A$ dislocated $S_{b}$-metric space is a pair $\left(X, S_{b}\right)$ such that $X$ is a nonempty set and $S_{b}$ is a dislocated $S_{b}$-metric on $X$. In the case that $b=1, S_{b}$ is denoted by $S$ and it is called dislocated $S$-metric, and the pair $(X, S)$ is called dislocated $S$-metric space.

Definition 2.2. Let $\left(X, S_{b}\right)$ be a dislocated $S_{b}$-metric space, $\left\{x_{n}\right\}$ be any sequence in $X$ and $x \in X$. Then:

(i) The sequence $\left\{x_{n}\right\}$ is said to be a Cauchy sequence in $\left(X, S_{b}\right)$ if, for each $\varepsilon>0$, there exists $n_{0} \in \mathbb{N}$ such that $S_{b}\left(x_{n}, x_{n}, x_{m}\right)<\varepsilon$ for each $m, n \geq n_{0}$. 
(ii) The sequence $\left\{x_{n}\right\}$ is said to be convergent to $x$ if, for each $\varepsilon>0$, there exists a positive integer $n_{0}$ such that $S_{b}\left(x, x, x_{n}\right)<\varepsilon$ for all $n \geq n_{0}$ and we denote it by $\lim _{n \rightarrow \infty} x_{n}=x$.

(iii) $\left(X, S_{b}\right)$ is said to be complete if every Cauchy sequence is convergent.

The following example shows that a dislocated $S_{b}$-metric need not be a dislocated $S$-metric.

Example 2.1. Let $X=\mathbb{R}_{+}$, then the mapping $S_{b}: X^{3} \rightarrow \mathbb{R}_{+}$defined by

$S_{b}(x, y, z)=x+y+4 z$ is a complete dislocated $S_{b}$-metric on $X$ with $b=2$. However, it is not a dislocated S-metric space. Indeed, we have

$$
4=S_{b}(0,0,1) \not 2 S_{b}(0,0,0)+S_{b}(1,1,0)=2 .
$$

Definition 2.3. Suppose that $\left(X, S_{b}\right)$ is a dislocated $S_{b}$-metric space. A mapping $T: X \rightarrow X$ is said to be a generalized $F$-contraction on $\left(X, S_{b}\right)$ if there exist $F \in \mathfrak{F}$ and $\tau>0$ such that for all $x, y \in X$,

$$
S_{b}(T x, T x, T y)>0 \Rightarrow \tau+F\left(b^{2} S_{b}(T x, T x, T y)\right) \leq F(N(x, y))
$$

where

$$
N(x, y)=\max \left\{S_{b}(x, x, y), S_{b}(T x, T x, T y), \frac{S_{b}(y, y, T x)}{10 b^{8}}, \frac{S_{b}(x, x, T y)}{10 b^{9}}, \frac{S_{b}\left(y, y, T^{2} x\right)}{10 b^{4}}\right\}
$$

Our first main result is the following.

Theorem 2.1. Let $\left(X, S_{b}\right)$ be a complete dislocated $S_{b}$-metric space and $T: X \rightarrow X$ be a generalized F-contraction mapping satisfying the following condition:

$$
\max \left\{\frac{S_{b}(y, y, T y)}{5 b^{7}}+\frac{S_{b}(T x, T x, T y)}{10 b^{7}}, \frac{S_{b}(x, x, T y)}{10 b^{9}}, \frac{S_{b}\left(y, y, T^{2} x\right)}{10 b^{4}}\right\} \leq S_{b}(T x, T x, T y)
$$

for all $x, y \in X$.

Then $T$ has a unique fixed point $v \in X$.

Proof. Let $x_{0}$ be an arbitrary point in $X$ and let $\left\{x_{n}\right\}$ be the Picard sequence of $\mathrm{T}$ based on $x_{0}$, that is, $x_{n+1}=T x_{n}$ for $n=0,1,2, \ldots$ If there exists $n_{0} \in \mathbb{N}$ such that $S_{b}\left(x_{n_{0}}, x_{n_{0}}, x_{n_{0+1}}\right)=0$, then $x_{n_{0}}$ is a fixed point of $T$ and the existence part of the proof is finished. On the contrary case, assume that $S_{b}\left(x_{n}, x_{n}, x_{n+1}\right)>0$ for all $n \in \mathbb{N} \cup\{0\}$. Applying the contractivity condition (2.1), we get

$$
F\left(b^{2} S_{b}\left(T x_{n-1}, T x_{n-1}, T x_{n}\right)\right) \leq F\left(N\left(x_{n-1}, x_{n}\right)\right)-\tau .
$$

Using the definition of $N(x, y)$ and the property $\left(d S_{b} 2\right)$, we obtain that

$$
\begin{aligned}
& \max \left\{S_{b}\left(x_{n-1}, x_{n-1}, x_{n}\right), S_{b}\left(x_{n}, x_{n}, x_{n+1}\right)\right\} \leq N\left(x_{n-1}, x_{n}\right) \\
= & \max \left\{S_{b}\left(x_{n-1}, x_{n-1}, x_{n}\right), S_{b}\left(x_{n}, x_{n}, T x_{n}\right), \frac{S_{b}\left(x_{n}, x_{n}, T x_{n-1}\right)}{10 b^{8}},\right. \\
& \left.\quad \frac{S_{b}\left(x_{n-1}, x_{n-1}, T x_{n}\right)}{10 b^{9}}, \frac{S_{b}\left(x_{n}, x_{n}, T x_{n}\right)}{10 b^{4}}\right\} \\
\leq & \max \left\{S_{b}\left(x_{n-1}, x_{n-1}, x_{n}\right), S_{b}\left(x_{n}, x_{n}, T x_{n}\right), \frac{3 S_{b}\left(x_{n}, x_{n}, x_{n+1}\right)}{10 b^{7}},\right. \\
& \left.\quad \frac{S_{b}\left(x_{n-1}, x_{n-1}, T x_{n}\right)}{10 b^{9}}, \frac{S_{b}\left(x_{n}, x_{n}, T x_{n}\right)}{10 b^{4}}\right\} \\
= & \max \left\{S_{b}\left(x_{n-1}, x_{n-1}, x_{n}\right), S_{b}\left(x_{n}, x_{n}, x_{n+1}\right)\right\}
\end{aligned}
$$


Then $N\left(x_{n-1}, x_{n}\right)=\max \left\{S_{b}\left(x_{n-1}, x_{n-1}, x_{n}\right), S_{b}\left(x_{n}, x_{n}, x_{n+1}\right)\right\}$ and so (2.2), becomes

$$
F\left(b^{2} S_{b}\left(T x_{n-1}, T x_{n-1}, T x_{n}\right)\right) \leq F\left(\max \left\{S_{b}\left(x_{n-1}, x_{n-1}, x_{n}\right), S_{b}\left(x_{n}, x_{n}, x_{n+1}\right)\right\}\right)-\tau .
$$

If we assume that

$$
\max \left\{S_{b}\left(x_{n-1}, x_{n-1}, x_{n}\right), S_{b}\left(T x_{n-1}, T x_{n-1}, T x_{n}\right)\right\}=S_{b}\left(T x_{n-1}, T x_{n-1}, T x_{n}\right)
$$

for some $n$, then we have

$$
\begin{aligned}
F\left(b^{2} S_{b}\left(T x_{n-1}, T x_{n-1}, T x_{n}\right)\right) & \leq F\left(S_{b}\left(T x_{n-1}, T x_{n-1}, T x_{n}\right)\right)-\tau \\
& <F\left(S_{b}\left(T x_{n-1}, T x_{n-1}, T x_{n}\right)\right) .
\end{aligned}
$$

Using condition (F1) we conclude that $S_{b}\left(x_{n}, x_{n}, x_{n+1}\right)<S_{b}\left(x_{n}, x_{n}, x_{n+1}\right)$, which is a contradiction. Therefore, for each $n \in \mathbb{N}$ we have

$$
\max \left\{S_{b}\left(x_{n-1}, x_{n-1}, x_{n}\right), S_{b}\left(x_{n}, x_{n}, x_{n+1}\right)\right\}=S_{b}\left(x_{n-1}, x_{n-1}, x_{n}\right) .
$$

Applying again (2.2) and condition $(F 1)$, we deduce that

$$
S_{b}\left(x_{n}, x_{n}, x_{n+1}\right)<S_{b}\left(x_{n-1}, x_{n-1}, x_{n}\right)
$$

for each $n$. Thus $\left\{S_{b}\left(x_{n}, x_{n}, x_{n+1}\right)\right\}$ is a nonnegative decreasing sequence of real numbers. Then there exists $A \geq 0$ such that

$$
\lim _{n \rightarrow+\infty} S_{b}\left(x_{n}, x_{n}, x_{n+1}\right)=\inf _{n \in \mathbb{N}} S_{b}\left(x_{n}, x_{n}, x_{n+1}\right)=A
$$

We claim that $A=0$. To support the claim, let it be untrue and $A>0$. Then, for any $\varepsilon>0$, it is possible to find a positive integer $m$ so that

$$
S_{b}\left(x_{m}, x_{m}, T x_{m}\right)<A+\varepsilon .
$$

So, from $(F 1)$, we get

$$
F\left(S_{b}\left(x_{m}, x_{m}, T x_{m}\right)\right)<F(A+\varepsilon) .
$$

It follows from (2.1) that

$$
\tau+F\left(b^{2} S_{b}\left(T x_{m}, T x_{m}, T^{2} x_{m}\right)\right) \leq F\left(N\left(x_{m}, T x_{m}\right)\right) .
$$

By a similar argument as (2.3), it yields that

$$
N\left(x_{m}, T x_{m}\right)=\max \left\{S_{b}\left(x_{m}, x_{m}, T x_{m}\right), S_{b}\left(T x_{m}, T x_{m}, T^{2} x_{m}\right)\right\} .
$$

Hence (2.5), becomes

$$
F\left(b^{2} S_{b}\left(T x_{m}, T x_{m}, T^{2} x_{m}\right)\right) \leq F\left(\max \left\{S_{b}\left(x_{m}, x_{m}, T x_{m}\right), S_{b}\left(T x_{m}, T x_{m}, T^{2} x_{m}\right)\right\}\right)-\tau .
$$

Now if, $\max \left\{S_{b}\left(x_{m}, x_{m}, T x_{m}\right), S_{b}\left(T x_{m}, T x_{m}, T^{2} x_{m}\right)\right\}=S_{b}\left(T x_{m}, T x_{m}, T^{2} x_{m}\right)$ for some $m$, then (2.6) gives us a contradiction. Thus, we infer that

$$
\max \left\{S_{b}\left(x_{m}, x_{m}, T x_{m}\right), S_{b}\left(T x_{m}, T x_{m}, T^{2} x_{m}\right)\right\}=S_{b}\left(x_{m}, x_{m}, T x_{m}\right)
$$


and therefore, we have

$$
F\left(b^{2} S_{b}\left(T x_{m}, T x_{m}, T^{2} x_{m}\right)\right) \leq F\left(S_{b}\left(x_{m}, x_{m}, T x_{m}\right)\right)-\tau
$$

It implies that

$$
\begin{aligned}
F\left(b^{2} S_{b}\left(T^{2} x_{m}, T^{2} x_{m}, T^{3} x_{m}\right)\right) & \leq F\left(S_{b}\left(T x_{m}, T x_{m}, T^{2} x_{m}\right)\right)-\tau \\
& \leq F\left(b^{2} S_{b}\left(T x_{m}, T x_{m}, T^{2} x_{m}\right)\right)-\tau \\
& \leq F\left(S_{b}\left(x_{m}, x_{m}, T x_{m}\right)\right)-2 \tau
\end{aligned}
$$

Continuing the above process and taking (2.4) into account, we deduce that

$$
\begin{aligned}
F\left(b^{2} S_{b}\left(T^{n} x_{m}, T^{n} x_{m}, T^{n+1} x_{m}\right)\right) & \leq F\left(S_{b}\left(T^{n-1} x_{m}, T^{n-1} x_{m}, T^{n} x_{m}\right)\right)-\tau \\
& \leq F\left(b^{2} S_{b}\left(T^{n-1} x_{m}, T^{n-1} x_{m}, T^{n} x_{m}\right)\right)-\tau \\
& \leq F\left(S_{b}\left(T^{n-2} x_{m}, T^{n-2} x_{m}, T^{n-1} x_{m}\right)\right)-2 \tau \\
& \vdots \\
& \leq F\left(S_{b}\left(x_{m}, x_{m}, T x_{m}\right)\right)-n \tau \\
& <F(A+\varepsilon)-n \tau
\end{aligned}
$$

and by passing to the limit as $n \rightarrow+\infty$ we obtain

$$
\lim _{n \rightarrow+\infty} F\left(b^{2} S_{b}\left(T^{n} x_{m}, T^{n} x_{m} \cdot T^{n+1} x_{m}\right)\right)=-\infty
$$

This fact together with the condition $(F 2)$ implies that

$$
\lim _{n \rightarrow+\infty} S_{b}\left(T^{n} x_{m}, T^{n} x_{m}, T^{n+1} x_{m}\right)=0 .
$$

Thus $S_{b}\left(T^{n} x_{m}, T^{n} x_{m}, T^{n+1} x_{m}\right)<A$ for $n$ sufficiently large, which is a contradiction with the definition of A. Then,

$$
\lim _{n \rightarrow+\infty} S_{b}\left(x_{n}, x_{n}, x_{n+1}\right)=0 .
$$

Next, we intend to show that the sequence $\left\{x_{n}\right\}$ is a Cauchy sequence in $X$. Arguing by contradiction, we assume that there exist $\varepsilon>0$, and subsequences $\left\{x_{q(n)}\right\}$ and $\left\{x_{p(n)}\right\}$ of $\left\{x_{n}\right\}$ with $n<q(n)<p(n)$ such that

$$
S_{b}\left(x_{q(n)}, x_{q(n)}, x_{p(n)}\right) \geq \varepsilon
$$

for each $n \in \mathbb{N}$. Further, corresponding to $q(n)$, we can choose $p(n)$ in such a way that it is the smallest integer with $q(n)<p(n)$ satisfying the above inequality, then

$$
S_{b}\left(x_{q(n)}, x_{q(n)}, x_{p(n)-1}\right)<\varepsilon
$$

for all $n \in \mathbb{N}$.

In the light of (2.8) and the condition (2.1), we conclude that

$$
F\left(b^{2} S_{b}\left(T x_{q(n)-1}, T x_{q(n)-1}, T x_{p(n)-1}\right)\right) \leq F\left(N\left(x_{q(n)-1}, x_{p(n)-1}\right)\right)-\tau .
$$


By our hypothesis and in view of $\left(d S_{b} 2\right)$, we get

$$
\begin{aligned}
\max \left\{S _ { b } \left(x_{q(n)-1}, x_{q(n)-1},\right.\right. & \left.\left.x_{p(n)-1}\right), S_{b}\left(T x_{q(n)-1}, T x_{q(n)-1}, T x_{p(n)-1}\right)\right\} \\
\leq & N\left(x_{q(n)-1}, x_{p(n)-1}\right) \\
= & \max \left\{S_{b}\left(x_{q(n)-1}, x_{q(n)-1}, x_{p(n)-1}\right), S_{b}\left(T x_{q(n)-1}, T x_{q(n)-1}, T x_{p(n)-1}\right),\right. \\
& \frac{S_{b}\left(x_{p(n)-1}, x_{p(n)-1}, T x_{q(n)-1}\right)}{10 b^{8}}, \frac{S_{b}\left(x_{q(n)-1}, x_{q(n)-1}, T x_{P(n)-1}\right)}{10 b^{9}}, \\
& \left.\frac{S_{b}\left(x_{p(n)-1}, x_{p(n)-1}, T x_{q(n)}\right)}{10 b^{4}}\right\} \\
\leq & \frac{\max \left\{S_{b}\left(x_{q(n)-1}, x_{q(n)-1}, x_{p(n)-1}\right), S_{b}\left(T x_{q(n)-1}, T x_{q(n)-1}, T x_{p(n)-1}\right)\right.}{5 b^{7}}, \\
& \frac{S_{b}\left(x_{p(n)-1}, x_{p(n)-1}, T x_{p(n)-1}\right)}{10}+\frac{S_{b}\left(T x_{q(n)-1}, T x_{q(n)-1}, T x_{p(n)-1}\right)}{10 b^{7}}, \\
\leq & \max \left\{S_{b(n)-1}, x_{q(n)-1}, T x_{P(n)-1}\right) \\
10 b^{9} & \left.\frac{S_{b}\left(x_{p(n)-1}, x_{p(n)-1}, T x_{q(n)}\right)}{10 b^{4}}\right\}
\end{aligned}
$$

It enforces that

$$
N\left(x_{q(n)-1}, x_{p(n)-1}\right)=\max \left\{S_{b}\left(x_{q(n)-1}, x_{q(n)-1}, x_{p(n)-1}\right), S_{b}\left(T x_{q(n)-1}, T x_{q(n)-1}, T x_{p(n)-1}\right)\right\} .
$$

Suppose that the maximum on the right-hand side is equal to $S_{b}\left(T x_{q(n)-1}, T x_{q(n)-1}, T x_{p(n)-1}\right)$ for some $n$, then from relation (2.10) together with the condition $(F 1)$ we get

$$
S_{b}\left(T x_{q(n)-1}, T x_{q(n)-1}, T x_{p(n)-1}\right)<S_{b}\left(T x_{q(n)-1}, T x_{q(n)-1}, T x_{p(n)-1}\right)
$$

which is a contradiction. Thus, we find that

$$
\left.\max \left\{x_{q(n)-1}, x_{q(n)-1}, x_{p(n)-1}\right), S_{b}\left(x_{q(n)}, x_{q(n)}, x_{p(n)}\right)\right\}=S_{b}\left(x_{q(n)-1}, x_{q(n)-1}, x_{p(n)-1}\right)
$$

for all $n$. Accordingly, (2.10) becomes

$$
F\left(b^{2} S_{b}\left(T x_{q(n)-1}, T x_{q(n)-1}, T x_{p(n)-1}\right)\right) \leq F\left(S_{b}\left(x_{q(n)-1}, x_{q(n)-1}, x_{p(n)-1}\right)\right)-\tau
$$

and so using $(F 1)$ we get

$$
S_{b}\left(x_{q(n)}, x_{q(n)}, x_{p(n)}\right)<S_{b}\left(x_{q(n)-1}, x_{q(n)-1}, x_{p(n)-1}\right) .
$$

Regarding to $(2.8),(2.12)$ and employing $\left(d S_{b} 2\right)$ we observe that

$$
\begin{aligned}
\varepsilon \leq & S_{b}\left(x_{q(n)}, x_{q(n)}, x_{p(n)}\right) \\
< & S_{b}\left(x_{q(n)-1}, x_{q(n)-1}, x_{p(n)-1}\right) \\
\leq & 2 b S_{b}\left(x_{q(n)-1}, x_{q(n)-1}, x_{q(n)}\right)+b S_{b}\left(x_{p(n)-1}, x_{p(n)-1}, x_{q(n)}\right) \\
\leq & 2 b S_{b}\left(x_{q(n)-1}, x_{q(n)-1}, x_{q(n)}\right)+2 b^{2} S_{b}\left(x_{p(n)-1}, x_{p(n)-1}, x_{p(n)-1}\right) \\
& +b^{2} S_{b}\left(x_{q(n)}, x_{q(n)}, x_{p(n)-1}\right) \\
\leq & 2 b S_{b}\left(x_{q(n)-1}, x_{q(n)-1}, x_{q(n)}\right)+6 b^{3} S_{b}\left(x_{p(n)-1}, x_{p(n)-1}, x_{p(n)}\right) \\
& +b^{2} S_{b}\left(x_{q(n)}, x_{q(n)}, x_{p(n)-1}\right) .
\end{aligned}
$$

Combining this result with (2.7) and (2.9) we get

$$
\varepsilon \leq \limsup _{n \rightarrow+\infty} S_{b}\left(x_{q(n)}, x_{q(n)}, x_{p(n)}\right) \leq \limsup _{n \rightarrow+\infty} S_{b}\left(x_{q(n)-1}, x_{q(n)-1}, x_{p(n)-1}\right) \leq b^{2} \varepsilon .
$$


In view of (2.13) and (2.11) and applying the conditions $(F 1)$ and $\left(F 3^{\prime}\right)$, we have

$$
\begin{aligned}
F\left(b^{2} \varepsilon\right) & \leq F\left(b^{2} \limsup _{n \rightarrow+\infty} S_{b}\left(x_{q((n)}, x_{q(n)}, x_{p(n)}\right)\right) \\
& \leq F\left(\limsup _{n \rightarrow+\infty} S_{b}\left(x_{q(n)-1}, x_{q(n)-1}, x_{p(n)-1}\right)\right)-\tau \\
& \leq F\left(b^{2} \varepsilon\right)-\tau .
\end{aligned}
$$

It is a contradiction with $\tau>0$, and therefore it follows that $\left\{x_{n}\right\}$ is a Cauchy sequence in $X$. By completeness of $\left(X, S_{b}\right),\left\{x_{n}\right\}$ converges to some point $v \in X$. Then, for each $\varepsilon>0$, there exists $N_{1} \in \mathbb{N}$ such that

$$
S_{b}\left(v, v, x_{n}\right)<\varepsilon
$$

for all $n \geq N_{1}$. We are going to show that $v$ is a fixed point of $T$. For this aim, we consider two following cases:

Case 1. If $S_{b}\left(T v, T v, T x_{n}\right)=0$ for some $n \geq N_{1}$, then from $\left(d S_{b} 2\right)$ we find that

$$
S_{b}(T v, T v, v) \leq 2 b S_{b}\left(T v, T v, T x_{n}\right)+b S_{b}\left(v, v, T x_{n}\right) \leq b \varepsilon
$$

Case 2. If $S_{b}\left(T v, T v, T x_{n}\right)>0$ for all $n \geq N_{1}$, then using (2.1), we get

$$
F\left(b^{2} S_{b}\left(T v, T v, T x_{n}\right)\right) \leq F\left(N\left(v, x_{n}\right)\right)-\tau .
$$

From our assumptions, and using $\left(d S_{b} 2\right)$, it follows that

$$
\begin{aligned}
& \max \left\{S_{b}\left(v, v, x_{n}\right), S_{b}\left(T v, T v, T x_{n}\right)\right\} \\
& \leq N\left(v, x_{n}\right) \\
&= \max \left\{S_{b}\left(v, v, x_{n}\right), S_{b}\left(T v, T v, T x_{n}\right), \frac{S_{b}\left(x_{n}, x_{n}, T v\right)}{10 b^{8}}, \frac{S_{b}\left(v, v, T x_{n}\right)}{10 b^{9}}, \frac{S_{b}\left(x_{n}, x_{n}, T^{2} v\right)}{10 b^{4}}\right\} \\
& \leq \max \left\{S_{b}\left(v, v, x_{n}\right), S_{b}\left(T v, T v, T x_{n}\right), \frac{S_{b}\left(x_{n}, x_{n}, T x_{n}\right)}{5 b^{7}}+\frac{S_{b}\left(T v, T v, T x_{n}\right)}{10 b^{7}},\right. \\
&\left.\frac{S_{b}\left(v, v, T x_{n}\right)}{10 b^{9}}, \frac{S_{b}\left(x_{n}, x_{n}, T^{2} v\right)}{10 b^{4}}\right\} \\
&= \max \left\{S_{b}\left(v, v, x_{n}\right), S_{b}\left(T v, T v, T x_{n}\right)\right\} .
\end{aligned}
$$

It enforces that $N\left(v, x_{n}\right)=\max \left\{S_{b}\left(v, v, x_{n}\right), S_{b}\left(T v, T v, T x_{n}\right)\right\}$. Now, if we assume that the maximum on the right-hand side of this equality is equal to $S_{b}\left(T v, T v, T x_{n}\right)$, then by replacing it in (2.15), we obtain $S_{b}\left(T v, T v, T x_{n}\right)<S_{b}\left(T v, T v, T x_{n}\right)$ which is a contradiction. Consequently, for each $n \in \mathbb{N}$ we have

$$
\max \left\{S_{b}\left(v, v, x_{n}\right), S_{b}\left(T v, T v, T x_{n}\right)\right\}=S_{b}\left(v, v, x_{n}\right) .
$$

Hence, (2.15) turns into

$$
\begin{aligned}
F\left(b^{2} S_{b}\left(T v, T v, T x_{n}\right)\right) & \leq F\left(S_{b}\left(v, v, x_{n}\right)\right)-\tau \\
& <F\left(S_{b}\left(v, v, x_{n}\right)\right) .
\end{aligned}
$$

Employing the condition $(F 1)$, we get

$$
S_{b}\left(T v, T v, T x_{n}\right)<S_{b}\left(v, v, x_{n}\right)
$$


From $\left(d S_{b} 2\right),(2.16)$ and $(2.14)$, we deduce that

$$
S_{b}(T v, T v, v) \leq 2 b S_{b}\left(T v, T v, T x_{N_{1}}\right)+b S_{b}\left(v, v, T x_{N_{1}}\right)<3 b \varepsilon
$$

From the arbitrariness of $\varepsilon$ in each case, it follows that $S_{b}(T v, T v, v)=0$ which implies that $T v=v$. Hence, $v$ is a fixed point of $T$.

Finally, we show that $T$ has at most one fixed point. Indeed, if $v_{1}, v_{2} \in X$ are two fixed points of $T$, such that $v_{1} \neq v_{2}$, then we obtain

$$
F\left(b^{2} S_{b}\left(T v_{1}, T v_{1}, T v_{2}\right)\right) \leq F\left(N\left(v_{1}, v_{2}\right)\right)-\tau
$$

From our hypothesis and by using $\left(d S_{b} 2\right)$, it follows that

$$
\begin{aligned}
S_{b}\left(v_{1}, v_{1}, v_{2}\right) \leq & N\left(v_{1}, v_{2}\right) \\
\leq & \max \left\{S_{b}\left(v_{1}, v_{1}, v_{2}\right), S_{b}\left(T v_{1}, T v_{1}, T v_{2}\right), \frac{S_{b}\left(v_{2}, v_{2}, T v_{2}\right)}{5 b^{7}}+\frac{S_{b}\left(T v_{1}, T v_{1}, T v_{2}\right)}{10 b^{7}}\right. \\
& \left.\frac{S_{b}\left(v_{1}, v_{1}, T v_{2}\right)}{10 b^{9}}, \frac{S_{b}\left(T v_{2}, T v_{2}, T^{2} v_{1}\right)}{10 b^{4}}\right\} \\
= & \max \left\{S_{b}\left(v_{1}, v_{1}, v_{2}\right), S_{b}\left(T v_{1}, T v_{1}, T v_{2}\right)\right\} \\
= & S_{b}\left(v_{1}, v_{1}, v_{2}\right) .
\end{aligned}
$$

Then (2.17) becomes

$$
F\left(b^{2} S_{b}\left(v_{1}, v_{1}, v_{2}\right)\right) \leq F\left(S_{b}\left(v_{1}, v_{1}, v_{2}\right)\right)-\tau
$$

It gives us a contradiction. Therefore, $v_{1}=v_{2}$ and the fixed point is unique.

Now we illustrate our result contained in Theorem 2.1 with help of two examples.

Example 2.2. Let $\left(X, S_{b}\right)$ be as in Example 2.1 and let $\tau>0$ be an arbitrary fixed number. Define the mapping $T: X \rightarrow X$ by $T(x)=e^{-\tau} \frac{x}{8}$ and take $F(\alpha)=\ln \alpha+\alpha(\alpha>0)$. It is easily verified that $N(x, y)=S_{b}(x, x, y)=2 x+4 y$. Assume that $x$ or $y$ is nonzero, then $S_{b}(T x, T x, T y)>0$ and we have

$$
\begin{aligned}
\tau+F\left(b^{2} S_{b}(T x, T x, T y)\right) & =\tau+\ln \left(e^{-\tau}(x+2 y)\right)+e^{-\tau}(x+2 y) \\
& =\ln (x+2 y)+e^{-\tau}(x+2 y) \\
& \leq \ln (2 x+4 y)+2 x+4 y \\
& =F\left(S_{b}(x, x, y)\right) \\
& =F(N(x, y)) .
\end{aligned}
$$

Hence, $T$ is a generalized $F$-contraction. On the other hand, if we assume that $0<\tau \leq 0.0250587314$, then the following estimate holds:

$$
\begin{gathered}
\max \left\{\frac{S_{b}(y, y, T y)}{5 b^{7}}+\frac{S_{b}(T x, T x, T y)}{10 b^{7}}, \frac{S_{b}(x, x, T y)}{10 b^{9}}, \frac{S_{b}\left(y, y, T^{2} x\right)}{10 b^{4}}\right\} \\
=\max \left\{\frac{2 y+e^{-\tau} \frac{y}{2}}{5 \times 2^{7}}+\frac{e^{-\tau}\left(\frac{x}{4}+\frac{y}{2}\right)}{10 \times 2^{7}}, \frac{2 x+e^{-\tau} \frac{y}{2}}{10 \times 2^{9}}, \frac{2 y+e^{-2 \tau} \frac{x}{16}}{10 \times 2^{4}}\right\} \\
\leq e^{-\tau}\left(\frac{x}{4}+\frac{y}{2}\right)=S_{b}(T x, T x, T y) .
\end{gathered}
$$

Thus all conditions of Theorem 2.1 hold and 0 is a unique fixed point of $T$. 
Example 2.3. Let $X=\mathbb{R}$, and $S_{b}: X^{3} \rightarrow \mathbb{R}_{+}$be a mapping defined by $S_{b}(x, y, z)=\frac{x^{2}}{2}+\frac{y^{2}}{2}+2 z^{2}$. Then $\left(X, S_{b}\right)$ is a complete dislocated $S_{b}$-metric with $b=2$. Define the mapping $T: X \rightarrow X$ by $T(x)=\frac{x}{3}$ and take $F(\alpha)=\ln \alpha(\alpha>0)$. It is easily checked that $N(x, y)=S_{b}(x, x, y)=$ $x^{2}+2 y^{2}$. Assume that $x$ or $y$ is nonzero, then $S_{b}(T x, T x, T y)>0$ and we have

$$
\tau+F\left(b^{2} S_{b}(T x, T x, T y)\right) \leq F(N(x, y)) \Leftrightarrow \ln \left(\frac{9}{4}\right) \geq \tau .
$$

Also, we observe that

$$
\begin{aligned}
\max \left\{\frac{S_{b}(y, y, T y)}{5 b^{7}}+\frac{S_{b}(T x, T x, T y)}{10 b^{7}}, \frac{S_{b}(x, x, T y)}{10 b^{9}}\right. & \left., \frac{S_{b}\left(y, y, T^{2} x\right)}{10 b^{4}}\right\} \\
& =\max \left\{\frac{48 y^{2}+2 x^{2}}{23040}, \frac{18 x^{2}+4 y^{2}}{92160}, \frac{162 y^{2}+4 x^{2}}{25920}\right\} \\
& \leq \frac{10240 x^{2}+20480 y^{2}}{92160} \\
& =S_{b}(T x, T x, T y)
\end{aligned}
$$

for all $x, y \in X$. Now, if we assume that $0<\tau \leq \ln \left(\frac{9}{4}\right)$, then all the conditions of Theorem 2.1 hold and 0 is a unique fixed point of $T$.

Now, we describe the concept of generalized $F$-Suzuki-contraction in the framework of dislocated $S_{b}$-metric spaces.

Definition 2.4. Let $\left(X, S_{b}\right)$ be a dislocated $S_{b}$-metric space. A mapping $T: X \rightarrow X$ is said to be a generalized $F$-Suzuki-contraction if there exists $F \in \mathfrak{F}$ such that for all $x, y \in X$

$$
\frac{1}{2 b} S_{b}(x, x, T x)<S_{b}(x, x, y) \Rightarrow F\left(2 b^{3} S_{b}(T x, T x, T y)\right) \leq F\left(M_{T}(x, y)\right)-\psi\left(M_{T}(x, y)\right),
$$

where $\psi \in \Psi$ and

$$
\begin{gathered}
M_{T}(x, y)=\max \left\{S_{b}(x, x, y), \frac{S_{b}(y, y, T y)}{10}, \frac{S_{b}(x, x, T x)}{10}, S_{b}(T x, T x, T y),\right. \\
\left.\frac{S_{b}(y, y, T x)}{18 b}, \frac{S_{b}\left(T x, T x, T^{2} x\right)}{2}\right\} .
\end{gathered}
$$

Our second main result is the following.

Theorem 2.2. Let $\left(X, S_{b}\right)$ be a complete dislocated $S_{b}$-metric space and $T: X \rightarrow X$ be a generalized F-Suzuki-contraction satisfying the following condition:

$$
\max \left\{\frac{S_{b}(y, y, T y)}{10}, \frac{S_{b}(x, x, T x)}{10}, \frac{S_{b}(y, y, T y)}{9}+\frac{S_{b}(T x, T x, T y)}{18}, \frac{S_{b}\left(T x, T x, T^{2} x\right)}{2}\right\} \leq S_{b}(T x, T x, T y)
$$

for all $x, y$ in $X$. Then $T$ has a unique fixed point in $X$.

Proof. Let $x_{0}$ be arbitrary. Define $x_{n}=T x_{n-1}$ for each $n \in \mathbb{N}$. If there exists $n \in \mathbb{N}$ such that $S_{b}\left(x_{n}, x_{n}, T x_{n}\right)=$ 0 , then $x_{n}=T x_{n}$ and $x_{n}$ becomes a fixed point of $T$, which completes the proof. Therefore, we assume that $S_{b}\left(x_{n}, x_{n}, T x_{n}\right)>0$ for all $n \in \mathbb{N}$. Taking into account (2.18), we deduce

$$
F\left(2 b^{3} S_{b}\left(T x_{n}, T x_{n}, T x_{n+1}\right)\right) \leq F\left(M_{T}\left(x_{n}, x_{n+1}\right)\right)-\psi\left(M_{T}\left(x_{n}, x_{n+1}\right)\right) .
$$


Using $\left(d S_{b} 2\right)$ we get

$$
\begin{aligned}
& \max \left\{S_{b}\left(x_{n}, x_{n}, x_{n+1}\right), S_{b}\left(x_{n+1}, x_{n+1}, T x_{n+1}\right)\right\} \\
& \leq M_{T}\left(x_{n}, x_{n+1}\right) \\
& \leq \max \left\{S_{b}\left(x_{n}, x_{n}, x_{n+1}\right), \frac{S_{b}\left(x_{n+1}, x_{n+1}, T x_{n+1}\right)}{10}, \frac{S_{b}\left(x_{n}, x_{n}, T x_{n}\right)}{10},\right. \\
&\left.S_{b}\left(T x_{n}, T x_{n}, T x_{n+1}\right), \frac{S_{b}\left(T x_{n}, T x_{n}, T x_{n+1}\right)}{2}, \frac{S_{b}\left(x_{n+1}, x_{n+1}, x_{n+2}\right)}{6}\right\} \\
&= \max \left\{S_{b}\left(x_{n}, x_{n}, x_{n+1}\right), S_{b}\left(x_{n+1}, x_{n+1}, x_{n+2}\right)\right\}
\end{aligned}
$$

and combining it with the relation (2.19) we derive

$$
\begin{aligned}
F\left(2 b^{3} S_{b}\left(T x_{n}, T x_{n}, T x_{n+1}\right)\right) \leq & F\left(\max \left\{S_{b}\left(x_{n}, x_{n}, x_{n+1}\right), S_{b}\left(x_{n+1}, x_{n+1}, x_{n+2}\right\}\right)\right. \\
& -\psi\left(\max \left\{S_{b}\left(x_{n}, x_{n}, x_{n+1}\right), S_{b}\left(x_{n+1}, x_{n+1}, x_{n+2}\right\}\right) .\right.
\end{aligned}
$$

If $\max \left\{S_{b}\left(x_{n}, x_{n}, x_{n+1}\right), S_{b}\left(x_{n+1}, x_{n+1}, x_{n+2}\right)\right\}=S_{b}\left(x_{n+1}, x_{n+1}, x_{n+2}\right)$, then (2.20) becomes

$$
F\left(2 b^{3} S_{b}\left(T x_{n}, T x_{n}, T x_{n+1}\right)\right) \leq F\left(S_{b}\left(x_{n+1}, x_{n+1}, x_{n+2}\right)\right)-\psi\left(S\left(x_{n+1}, x_{n+1}, x_{n+2}\right)\right) .
$$

By the property of $\psi$ and using condition $(F 1)$, we obtain

$$
2 b^{3} S_{b}\left(T x_{n}, T x_{n}, T x_{n+1}\right)<S_{b}\left(T x_{n}, T x_{n}, T x_{n+1}\right)
$$

which is a contradiction. Hence $\max \left\{S_{b}\left(x_{n}, x_{n}, x_{n+1}\right), S_{b}\left(x_{n+1}, x_{n+1}, x_{n+2}\right)\right\}=S_{b}\left(x_{n}, x_{n}, x_{n+1}\right)$, then (2.20) becomes

$$
F\left(2 b^{3} S_{b}\left(T x_{n}, T x_{n}, T x_{n+1}\right)\right) \leq F\left(S_{b}\left(x_{n}, x_{n}, x_{n+1}\right)\right)-\psi\left(S\left(x_{n}, x_{n}, x_{n+1}\right)\right) .
$$

This together with condition $(F 1)$ implies that $S_{b}\left(T x_{n}, T x_{n}, T x_{n+1}\right)<S_{b}\left(x_{n}, x_{n}, x_{n+1}\right)$ for each $n \in \mathbb{N}$. Then $\left\{S_{b}\left(x_{n}, x_{n}, x_{n+1}\right)\right\}$ is a nonnegative decreasing sequence of real numbers. Therefore, there exists $A \geq 0$ such that $\lim _{n \rightarrow+\infty} S_{b}\left(x_{n}, x_{n}, x_{n+1}\right)=A$.

Letting $n \rightarrow+\infty$ in $(2.21)$ and using $\left(F 3^{\prime}\right)$ and continuity of $\psi$, we get

$$
F\left(2 b^{3} A\right) \leq F(A)-\psi(A)
$$

It gives us $\psi(A)=0$. By property of $\psi$ we deduce that $A=0$. Consequently, we have

$$
\lim _{n \rightarrow+\infty} S_{b}\left(x_{n}, x_{n}, x_{n+1}\right)=0
$$

Next, we prove that $\left\{x_{n}\right\}$ is a Cauchy sequence in $X$. If it is not true, then there exist $\varepsilon>0$ and increasing sequences of natural numbers $\{p(n)\}$ and $\{q(n)\}$ such that

$$
\begin{gathered}
n<q(n)<p(n), \\
S_{b}\left(x_{q(n)}, x_{q(n)}, x_{p(n)}\right) \geq \varepsilon, \\
S_{b}\left(x_{q(n)}, x_{q(n)}, x_{p(n)-1}\right)<\varepsilon
\end{gathered}
$$

for all $n \in \mathbb{N}$.

Owing to (2.22), there exists $N_{1} \in \mathbb{N}$ such that

$$
S_{b}\left(x_{q(n)}, x_{q(n)}, T x_{q(n)}\right)<\varepsilon
$$


for all $n \geq N_{1}$. Hence, from (2.23) and (2.24) it follows that

$$
\frac{1}{2 b} S_{b}\left(x_{q(n)}, x_{q(n)}, T x_{q(n)}\right)<\frac{1}{2 b} \varepsilon<S_{b}\left(x_{q(n)}, x_{q(n)}, x_{p(n)}\right)
$$

for all $n \geq N_{1}$. By using (2.18) we obtain

$$
F\left(2 b^{3} S_{b}\left(T x_{q(n)}, T x_{q(n)}, T x_{p(n)}\right)\right) \leq F\left(M_{T}\left(x_{q(n)}, x_{p(n)}\right)\right)-\psi\left(M_{T}\left(x_{q(n)}, x_{p(n)}\right)\right) .
$$

From our assumptions and regarding $\left(d S_{b} 2\right)$, we get

$$
\begin{aligned}
& \max \left\{S_{b}\left(x_{q(n)}, x_{q(n)}, x_{p(n)}\right), S_{b}\left(T x_{q(n)}, T x_{q(n)}, T x_{p(n)}\right)\right\} \\
& \leq M_{T}\left(x_{q(n)}, x_{p(n)}\right) \\
& \leq \max \left\{S_{b}\left(x_{q(n)}, x_{q(n)}, x_{p(n)}\right), \frac{S_{b}\left(x_{p(n)}, x_{p(n)}, x_{p(n)+1}\right)}{10}, S_{b}\left(T x_{q(n)}, T x_{q(n)}, T x_{p(n)}\right)\right. \\
& \frac{S_{b}\left(x_{q(n)}, x_{q(n)}, x_{q(n)+1}\right)}{10}, \frac{S_{b}\left(x_{q(n)+1}, x_{q(n)+1}, x_{q(n)+2}\right)}{2}, \\
&\left.\frac{S_{b}\left(x_{p(n)}, x_{p(n)}, x_{p(n)+1}\right)}{9}+\frac{S_{b}\left(x_{q(n)+1}, x_{q(n)+1}, x_{p(n)+1}\right)}{18}\right\} \\
& \leq \max \left\{S_{b}\left(x_{q(n)}, x_{q(n)}, x_{p(n)}\right), S_{b}\left(x_{q(n)+1}, x_{q(n)+1}, x_{p(n)+1}\right)\right\} .
\end{aligned}
$$

Then (2.25) becomes

$F\left(2 b^{3} S_{b}\left(T x_{q(n)}, T x_{q(n)}, T x_{p(n)}\right)\right)$

$$
\begin{aligned}
& \leq F\left(\max \left\{S_{b}\left(x_{q(n)}, x_{q(n)}, x_{p(n)}\right), S_{b}\left(x_{q(n)+1}, x_{q(n)+1}, x_{p(n)+1}\right)\right\}\right) \\
& -\quad \psi\left(\max \left\{S_{b}\left(x_{q(n)}, x_{q(n)}, x_{p(n)}\right), S_{b}\left(x_{q(n)+1}, x_{q(n)+1}, x_{p(n)+1}\right)\right\}\right) .
\end{aligned}
$$

If $\max \left\{S_{b}\left(x_{q(n)}, x_{q(n)}, x_{p(n)}\right), S_{b}\left(x_{q(n)+1}, x_{q(n)+1}, x_{p(n)+1}\right)\right\}=S_{b}\left(x_{q(n)+1}, x_{q(n)+1}, x_{p(n)+1}\right)$ for some $n$, then we have

$$
\begin{aligned}
F\left(2 b^{3} S_{b}\left(T x_{q(n)}, T x_{q(n)}, T x_{p(n)}\right)\right) & \leq F\left(S_{b}\left(x_{q(n)+1}, x_{q(n)+1}, x_{p(n)+1}\right)\right) \\
& -\psi\left(S_{b}\left(x_{q(n)+1}, x_{q(n)+1}, x_{p(n)+1}\right)\right) .
\end{aligned}
$$

Obviously, $S_{b}\left(x_{q(n)+1}, x_{q(n)+1}, x_{p(n)+1}\right)>0$ and by the property of $\psi$ and $(F 1)$, we get

$$
S_{b}\left(T x_{q(n)}, T x_{q(n)}, T x_{p(n)}\right)<S_{b}\left(x_{q(n)+1}, x_{q(n)+1}, x_{p(n)+1}\right),
$$

which is a contradiction. Duo to this fact, we find that

$$
\max \left\{S_{b}\left(x_{q(n)}, x_{q(n)}, x_{p(n)}\right), S_{b}\left(x_{q(n)+1}, x_{q(n)+1}, x_{p(n)+1}\right)\right\}=S_{b}\left(x_{q(n)}, x_{q(n)}, x_{p(n)}\right)
$$

for all $n$. Therefore

$$
F\left(2 b^{3} S_{b}\left(T x_{q(n)}, T x_{q(n)}, T x_{p(n)}\right)\right) \leq F\left(S_{b}\left(x_{q(n)}, x_{q(n)}, x_{p(n)}\right)\right)-\psi\left(S_{b}\left(x_{q(n)}, x_{q(n)}, x_{p(n)}\right)\right),
$$

and by $(F 1)$, it follows that

$$
S_{b}\left(x_{q(n)+1}, x_{q(n)+1}, x_{p(n)+1}\right)<S_{b}\left(x_{q(n)}, x_{q(n)}, x_{p(n)}\right) .
$$


In view of $(2.23)$ and $\left(d S_{b} 2\right)$, we infer that

$$
\begin{aligned}
\varepsilon \leq & S_{b}\left(x_{q(n)}, x_{q(n)}, x_{p(n)}\right) \leq 2 b S_{b}\left(x_{q(n)}, x_{q(n)}, x_{p(n)-1}\right)+b S_{b}\left(x_{p(n)}, x_{p(n)}, x_{p(n)-1}\right) \\
\leq & 2 b S_{b}\left(x_{q(n)}, x_{q(n)}, x_{p(n)-1}\right)+2 b^{2} S_{b}\left(x_{p(n)}, x_{p(n)}, x_{p(n)}\right)+b^{2} S_{b}\left(x_{p(n)-1}, x_{p(n)-1}, x_{p(n)}\right) \\
\leq & 2 b S_{b}\left(x_{q(n)}, x_{q(n)}, x_{p(n)-1}\right)+6 b^{3} S_{b}\left(x_{p(n)}, x_{p(n)}, x_{p(n)+1}\right) \\
& +b^{2} S_{b}\left(x_{p(n)-1}, x_{p(n)-1}, x_{p(n)}\right) .
\end{aligned}
$$

Taking the limit as $n \rightarrow+\infty$ in the above inequality and regarding (2.22) and (2.23), we deduce that

$$
\varepsilon \leq \lim _{n \rightarrow+\infty} S_{b}\left(x_{q(n)}, x_{q(n)}, x_{p(n)}\right) \leq 2 b \varepsilon
$$

On the other hand, we have

$$
\begin{aligned}
\varepsilon \leq & S_{b}\left(x_{q(n)}, x_{q(n)}, x_{p(n)}\right) \leq 2 b S_{b}\left(x_{q(n)}, x_{q(n)}, x_{q(n)+1}\right)+b S_{b}\left(x_{p(n)}, x_{p(n)}, x_{q(n)+1}\right) \\
\leq \quad & 2 b S_{b}\left(x_{q(n)}, x_{q(n)}, x_{q(n)+1}\right)+2 b^{2} S_{b}\left(x_{p(n)}, x_{p(n)}, x_{p(n)+1}\right) \\
& +b^{2} S_{b}\left(x_{q(n)+1}, x_{q(n)+1}, x_{p(n)+1}\right) .
\end{aligned}
$$

Taking the limit supremum as $n \rightarrow+\infty$ in the above inequality. By using (2.22) we obtain

$$
\frac{\varepsilon}{b^{2}} \leq \limsup _{n \rightarrow+\infty} S_{b}\left(x_{q(n)+1}, x_{q(n)+1}, x_{p(n)+1}\right)
$$

Taking the limit supremum as $n \rightarrow+\infty$ on each side of (2.26) and using conditions (2.27) and (2.28) together with $(F 1)$ and $\left(F 3^{\prime}\right)$, we deduce that

$$
\begin{aligned}
F(2 b \varepsilon)=F\left(2 b^{3} \frac{\varepsilon}{b^{2}}\right) \leq & F\left(2 b^{3} \limsup _{n \rightarrow+\infty} S_{b}\left(x_{q(n)+1}, S_{b}\left(x_{q(n)+1}, x_{p(n)+1}\right)\right)\right. \\
\leq & F\left(\limsup _{n \rightarrow+\infty} S_{b}\left(x_{q(n)}, S_{b}\left(x_{q(n)}, x_{p(n)}\right)\right)\right. \\
& -\psi\left(\liminf _{n \rightarrow+\infty} S_{b}\left(x_{q(n)}, S_{b}\left(x_{q(n)}, x_{p(n)}\right)\right)\right. \\
\leq & F(2 b \varepsilon)-\psi(\varepsilon) .
\end{aligned}
$$

It enforces that $\psi(\varepsilon)=0$, which leads to a contradiction. Therefore $\left\{x_{n}\right\}$ is a Cauchy sequence in $X$. Since $X$ is a complete dislocated $S_{b}$-metric space, it follows that there exists $v \in X$ in which for each $\varepsilon>0$, there exists $N_{2} \in \mathbb{N}$ such that

$$
S_{b}\left(v, v, x_{n}\right)<\varepsilon
$$

for all $n>N_{2}$. Now, we prove that $v$ is a fixed point of $T$. To this end, we show that $S_{b}(T v, T v, v)=0$.

We consider the following cases:

Case 1. If $S_{b}\left(v, v, x_{n}\right)=0$ for sufficiently large $n$, then $v=x_{n}$. Thus, for sufficiently large $n$, we can write

$$
S_{b}(T v, T v, v)=S_{b}\left(T x_{n}, T x_{n}, v\right) \leq 2 b S_{b}\left(x_{n+1}, x_{n+1}, x_{n+2}\right)+b S_{b}\left(v, v, x_{n+2}\right) .
$$


Letting $n \rightarrow+\infty$ in the above inequality. From (2.22) and (2.29) we get $S_{b}(T v, T v, v)=0$. Thus $T v=v$ and $v$ is a fixed point of $T$.

Case 2. If there exists $n \geq N_{2}$ such that $S_{b}\left(v, v, x_{n}\right)>0$ and $S_{b}\left(T v, T v, T x_{n}\right)=0$, then from $\left(d S_{b} 2\right)$ we have

$$
S_{b}(T v, T v, v) \leq 2 b S_{b}\left(T v, T v, T x_{n}\right)+b S_{b}\left(v, v, x_{n+1}\right) \leq b \varepsilon,
$$

which implies that $T v=v$ by virtue of the arbitrariness of $\varepsilon$.

Case 3. If $S_{b}\left(v, v, x_{n}\right)>0$ and $S_{b}\left(T v, T v, T x_{n}\right)>0$ for all $n \geq N_{2}$, then using (2.18) we obtain

$$
F\left(2 b^{3} S_{b}\left(T v, T v, T x_{n}\right)\right) \leq F\left(M_{T}\left(v, x_{n}\right)\right)-\psi\left(M_{T}\left(v, x_{n}\right)\right) .
$$

Thus, by using the hypothesis and taking into account $\left(d S_{b} 2\right)$, it yields $\max \left\{S_{b}\left(v, v, x_{n}\right), S_{b}\left(T v, T v, T x_{n}\right)\right\}$

$$
\begin{aligned}
\leq & M_{T}\left(v, x_{n}\right) \\
\leq & \max \left\{S_{b}\left(v, v, x_{n}\right), S_{b}\left(T v, T v, T x_{n}\right), \frac{S_{b}\left(x_{n}, x_{n}, T x_{n}\right)}{10}\right. \\
& \left.\frac{S_{b}(v, v, T v)}{10}, \frac{S_{b}\left(x_{n}, x_{n}, T x_{n}\right)}{9}+\frac{S_{b}\left(T v, T v, T x_{n}\right)}{18}, \frac{S_{b}\left(T v, T v, T^{2} v\right)}{2}\right\} \\
\leq & \max \left\{S_{b}\left(v, v, x_{n}\right), S_{b}\left(T v, T v, T x_{n}\right)\right\} .
\end{aligned}
$$

Then (2.30) becomes

$$
\begin{aligned}
F\left(2 b^{3} S_{b}\left(T v, T v, T x_{n}\right)\right) & \leq F\left(\max \left\{S_{b}\left(v, v, x_{n}\right), S_{b}\left(T v, T v, T x_{n}\right)\right\}\right) \\
& -\psi\left(\max \left\{S_{b}\left(v, v, x_{n}\right), S_{b}\left(T v, T v, T x_{n}\right)\right\}\right) .
\end{aligned}
$$

If $\max \left\{S_{b}\left(v, v, x_{n}\right), S_{b}\left(T v, T v, T x_{n}\right)\right\}=S_{b}\left(T v, T v, T x_{n}\right)$, then we have

$$
F\left(2 b^{3} S_{b}\left(T v, T v, T x_{n}\right)\right) \leq F\left(S_{b}\left(T v, T v, T x_{n}\right)\right)-\psi\left(S_{b}\left(T v, T v, T x_{n}\right)\right) .
$$

From this it follows that $2 b^{3} S_{b}\left(T v, T v, T x_{n}\right)<S_{b}\left(T v, T v, T x_{n}\right)$, which is a contradiction. Therefore,

$$
\max \left\{S_{b}\left(v, v, x_{n}\right), S_{b}\left(T v, T v, T x_{n}\right)\right\}=S_{b}\left(v, v, x_{n}\right)
$$

and (2.30) becomes

$$
\begin{aligned}
F\left(2 b^{3} S_{b}\left(T v, T v, T x_{n}\right)\right) & \leq F\left(S_{b}\left(v, v, x_{n}\right)\right)-\psi\left(S_{b}\left(v, v, x_{n}\right)\right) \\
& <F\left(S_{b}\left(v, v, x_{n}\right)\right) .
\end{aligned}
$$

Thus, from $(F 1)$ we get

$$
S_{b}\left(T v, T v, T x_{n}\right)<S_{b}\left(v, v, x_{n}\right) .
$$

Applying (2.29), (2.31) and $\left(d S_{b} 2\right)$ we get

$$
S_{b}(T v, T v, v) \leq 2 b S_{b}\left(T v, T v, T x_{n}\right)+b S_{b}\left(v, v, x_{n+1}\right)<3 b \varepsilon
$$

for sufficiently large $n$. It enforces that $T v=v$ by virtue of the arbitrariness of $\varepsilon$. Then $v$ is a fixed point of $T$. 
Next, we show the uniqueness. Indeed, if $v_{1}, v_{2}$ are two fixed points of $T$ such that $v_{1} \neq v_{2}$, then in view of (2.18) we get

$$
F\left(2 b^{3} S_{b}\left(T v_{1}, T v_{1}, T v_{2}\right)\right) \leq F\left(M_{T}\left(v_{1}, v_{2}\right)\right)-\psi\left(M_{T}\left(v_{1}, v_{2}\right)\right)
$$

According to our assumptions and by using $\left(d S_{b} 2\right)$, we find that

$$
\begin{aligned}
S_{b}\left(v_{1}, v_{1}, v_{2}\right) \leq & M_{T}\left(v_{1}, v_{2}\right) \\
\leq & \max \left\{S_{b}\left(v_{1}, v_{1}, v_{2}\right), S_{b}\left(T v_{1}, T v_{1}, T v_{2}\right),\right. \\
& \frac{S_{b}\left(v_{2}, v_{2}, T v_{2}\right)}{10}, \frac{S_{b}\left(v_{1}, v_{1}, T v_{1}\right)}{10}, \frac{S_{b}\left(v_{2}, v_{2}, T v_{2}\right)}{9} \\
& \left.+\frac{S_{b}\left(T v_{1}, T v_{1}, T v_{2}\right)}{18}\right\} \\
\leq & \max \left\{S_{b}\left(v_{1}, v_{1}, v_{2}\right), S_{b}\left(T v_{1}, T v_{1}, T v_{2}\right)\right\} \\
= & S_{b}\left(v_{1}, v_{1}, v_{2}\right) .
\end{aligned}
$$

Then (2.32) becomes

$$
F\left(2 b^{3} S_{b}\left(v_{1}, v_{1}, v_{2}\right)\right) \leq F\left(S_{b}\left(v_{1}, v_{1}, v_{2}\right)\right)-\psi\left(S_{b}\left(v_{1}, v_{1}, v_{2}\right)\right)
$$

From this it follows that $2 b^{3} S_{b}\left(v_{1}, v_{1}, v_{2}\right)<S_{b}\left(v_{1}, v_{1}, v_{2}\right)$, which is a contradiction. Then $v_{1}=v_{2}$ and so $T$ has a unique fixed point in $X$.

Example 2.4. Let $X=\{-1,0,1\}$. Define the mapping $S_{b}: X^{3} \rightarrow \mathbb{R}_{+}$by

$$
S_{b}(x, y, z)= \begin{cases}\frac{3}{2}, & 0=x=y \neq z=1 \text { or }-1=x=y \neq z=1 \\ \frac{10}{6}, & 1=x=y \neq z \\ 0, & x=y=z=-1 \text { or } 1 \\ \frac{1}{5}, & \text { otherwise }\end{cases}
$$

for all $x, y, z \in X$. It is easy to show that $\left(X, S_{b}\right)$ is a complete dislocated $S_{b}$-metric space with $b=\frac{3}{2}$. Put $F(\alpha)=\ln \alpha(\alpha>0)$ and $\psi(t)=t(t \geq 0)$. Define $T: X \rightarrow X$ by

$$
T(x)= \begin{cases}0, & x=1 \\ -1, & x=-1,0\end{cases}
$$

Note that $S_{b}(x, x, y)>0$ and $S_{b}(T(x), T(x), T(y))>0$ if and only if $x \in\{-1,0\}, y=1$ or $x=1, y \in$ $\{-1,0\}$. Also, for each $x, y \in X$ we have $M_{T}(x, y)=S_{b}(x, x, y)$ and we find that

$$
F\left(2 b^{3} S_{b}(T(x), T(x), T(y))\right) \leq F\left(S_{b}(x, x, y)\right)-\psi\left(S_{b}(x, x, y)\right) \Leftrightarrow \ln \frac{S_{b}(x, x, y)}{2 b^{3} S_{b}(T(x), T(x), T(y))} \geq S_{b}(x, x, y) .
$$

Now, we consider two cases: 
Case 2.1. Case 1. Let $x \in\{-1,0\}$ and $y=1$, then

$$
\begin{gathered}
S_{b}(x, x, y)=\frac{3}{2}, \\
S_{b}(T(x), T(x), T(y))=S_{b}(-1,-1,0)=\frac{1}{5}, \\
S_{b}(0,0, T(0))=\frac{1}{5}, S_{b}(-1,-1, T(-1))=0 .
\end{gathered}
$$

So, we have

$$
\ln \frac{S_{b}(x, x, y)}{2 b^{3} S_{b}(T(x), T(x), T(y))}=\ln \frac{\frac{3}{2}}{\frac{54}{40}}=\ln \frac{120}{108}=3.0377 \geq S_{b}(x, x, y)=\frac{3}{2} .
$$

Case 2. Let $x=1$ and $y \in\{-1,0\}$, then

$$
\begin{gathered}
S_{b}(x, x, y)=\frac{10}{6}, \\
S_{b}(T(x), T(x), T(y))=\frac{1}{5}, \\
S_{b}(x, x, T(x))=\frac{10}{6} .
\end{gathered}
$$

So, we have

$$
\ln \frac{S_{b}(x, x, y)}{2 b^{3} S_{b}(T(x), T(x), T(y))}=\ln \frac{\frac{10}{6}}{\frac{54}{40}}=\ln \frac{400}{324}=3.4369 \geq S_{b}(x, x, y)=\frac{10}{6} .
$$

On the other hand, for all $x, y \in X$ we have

$$
\begin{aligned}
\max \left\{\frac{S_{b}(y, y, T(y))}{10}, \frac{S_{b}(x, x, T(x))}{10}\right. & \left., \frac{S_{b}(y, y, T(y))}{9}+\frac{S_{b}(T(x), T(x), T(y))}{18}, \frac{S_{b}\left(T(x), T(x), T^{2}(x)\right)}{2}\right\} \\
\leq & \frac{1}{5}=S_{b}(T(x), T(x), T(y)) .
\end{aligned}
$$

Hence, $T$ is a generalized F-Suzuki-contraction which satisfies the assumption of Theorem 2.2 and so it has a unique fixed point -1 .

\section{REFERENCES}

[1] I. A. Bakhtin, The contraction mapping principle in almost metric spaces, Funct. Anal. Unianowsk Gos. Ped. Inst. 30 (1989), 26-37.

[2] S. Czerwik, Contraction mappings in b-metric spaces, Acta Math. Inform. Univ. Ostra. 1 (1993), 5-11.

[3] N.V. Dung and V.L. Hang, A fixed point theorem for generalized F-contractions on complete metric spaces, Vietnam J. Math. 43 (2015), 743-753.

[4] G.N.V. Kishore, K.P.R. Rao, D. Panthi, B. Srinuvasa Rao and S. Satyanaraya, Some applications via fixed point results in partially ordered $S_{b}$-metric spaces, Fixed Point Theory Appl. 2017 (2017), 10.

[5] H. Piri and P. Kumam, Some fixed point theorems concerning $F$-contraction in complete metric spaces, Fixed Point Theory Appl. 2014 (2014), 210.

[6] H. Piri and P. Kumam, Fixed point theorems for generalized $F$-Suzuki-contraction mappings in complete $b$-metric spaces, Fixed Point Theory Appl. 2016 (2016), 90 .

[7] N.Y. Özgür and N. TaŞ, Some fixed point theorems on S-metric spaces, Mat. Vesnik 69 (1) (2017), 39-52.

[8] N.Y. Özgür, N. TaŞ and U. Celik, New fixed point-circle results on S-metric spaces, Bull. Math. Anal. Appl. 9 (2) (2017), $10-23$.

[9] Y. Rohená, T. Došenović and S. Radenović, A note on the paper "A Fixed point Theorems in $S_{b}$-Metric Spaces", Filomal 31 (11) (2017), 3335-3346. 
[10] Sh. Sedghi, A. Gholidahne, T. Došenovic, J. Esfahani and S. Radenovic, Common fixed point of four maps in $S_{b}$-metric spaces, J. Linear Topol. Alg. 5 (2) (2016), 93-104.

[11] Sh. Sedghi, N. Shobe and A. Aliouche, A generalization of fixed point theorem in S-metric spaces, Mat. Vesn. 64 (2012), 258-266.

[12] D. Wardowski, Fixed points of a new type of contractive mappings in complete metric spaces, Fixed Point Theory Appl. 2012 (2012), 94.

[13] D. Wardowski and N.V. Dung, Fixed points of $F$-weak contractions on complete metric spaces, Demonstr. Math. 47 (1) (2014), 146-155. 